\title{
Experimental and Predicted Rigid Rotor Stability Threshold of Axial Groove and Three-Lobe Bearings
}

\author{
R. D. FLACK ${ }^{1, *}$, G. J. KOSTRZEWSKY ${ }^{2}$, and L. E. BARRETT ${ }^{3}$ \\ ${ }^{1}$ Mechanical and Aerospace Engineering, University of Virginia, Charlottesville, Virginia 22903-2442, USA; \\ ${ }^{2}$ Cummins Engine Co., Columbus, Indiana, USA; ${ }^{3}$ University of Virginia, Charlottesville, Virginia, USA
}

\begin{abstract}
The measured performances of axial groove and preloaded three-lobe journal bearings are compared with the predicted performance. Operating eccentricity and dynamic coefficients were found for different shaft speeds and various steady loads. Numerical results are based on a Reynolds equation solver, which allows for a variety of thermal effects. Sinusoidal excitations were used to experimentally determine the eight linearized stiffness and damping coefficients. The rigid rotor stability threshold parameter, $\omega_{s}$, and whirl ratio, $\omega_{d}$, were found from the dynamic coefficients. The experimental and theoretical stability threshold and whirl ratio are correlated as independent functions of both the Sommerfeld number and operating eccentricity. The predicted stability maps are slightly higher than measured, indicating that the predicted characteristics are more stable than measured. The predicted whirl ratios are in approximate agreement with measured values. As expected, the stability maps show the axial groove bearings to be less stable than the preloaded three-lobe bearings.
\end{abstract}

Keywords: Hydrodynamic bearings; Bearing stability; Experimental bearing coefficients; Three-lobe bearings

The unbalance response and stability of rotor-bearing systems are strongly influenced by fluid film bearing design. Namely, the dynamic characteristics of the bearings have a direct impact on a machines dynamic performance. Design methodologies for bearing selection and performance prediction have previously received widespread use. Most such analyses were, however, developed before detailed data for bearing dynamic coefficients were available. Many of the previous experimental studies have focused on the

Received in final form 28 April 2000.

The ROMAC Industrial Research Program at the University of Virginia sponsored this research.

*Corresponding author. Fax: (804) 982-2037, e-mail: rdf@virginia.edu static behavior of bearings. However, although the experimental determination of the eight linearized dynamic coefficients of fluid film journal bearings has recently received more attention, the implications toward stability have not.

Flack et al. (1993); Kostrzewsky et al. (1994); Taylor et al. (1995a,b); Kostrzewsky et al. (1996) and Swanson and Kirk (1997) have effectively reviewed the experimental and theoretical research on the static and dynamic characteristics of different geometries of hydrodynamic journal bearings. In general, considerable scatter is shown in the previous data for dynamic coefficients.

Earlier investigations of the static and dynamic coefficient performance of a plain 2-axial groove journal bearing (Kostrzewsky et al., 1996) and of a fixed pad three-lobe bearing (Kostrzewsky et al., 1998; Flack and Kostrzewsky, 1998) provide the basis for this effort. The axial groove bearing is a very commonly used bearing because of the simplicity and the three-lobe geometry has excellent stability controlling characteristics, as shown by Lanes and Flack (1982).

The purpose of this paper is to extend previous comparisons by examining the measured and predicted stability performance of an axial groove and a fixed pad three-lobe geometry bearing. Rather than simply presenting the detailed information on individual coefficients, results presented herein represent an improvement over past work in that the dynamic coefficients are used to generate stability maps. Furthermore, previously unavailable comparisons of experimental stability maps of the two bearing types are presented.

\section{EXPERIMENTAL RIG}

The test rig, test procedure, and the data reduction is extensively documented by Flack et al. (1993). In summary, steady operating positions were varied by adjusting shaft speed and static load with a two axis static load system as 
shown in Figures 1 and 2. A cutaway view of the fixture is presented and the test bearing and housing are shown in Figure 1. In Figure 2 the overall load system is shown. Static and dynamic loads were applied to the bearing housing. The sinusoidal forces needed to derive the dynamic stiffness and damping coefficients were applied by a two-axis shaker system, which can be driven over a range of frequencies. Small, independent elliptical displacement orbits were produced for the different static equilibrium positions. Uncertainties were computed for the derived coefficients based on the uncertainties in the directly measured parameters. Flack et al. (1993) document the sources of uncertainty, their propagation, and the methods used to compute experimental uncertainty.

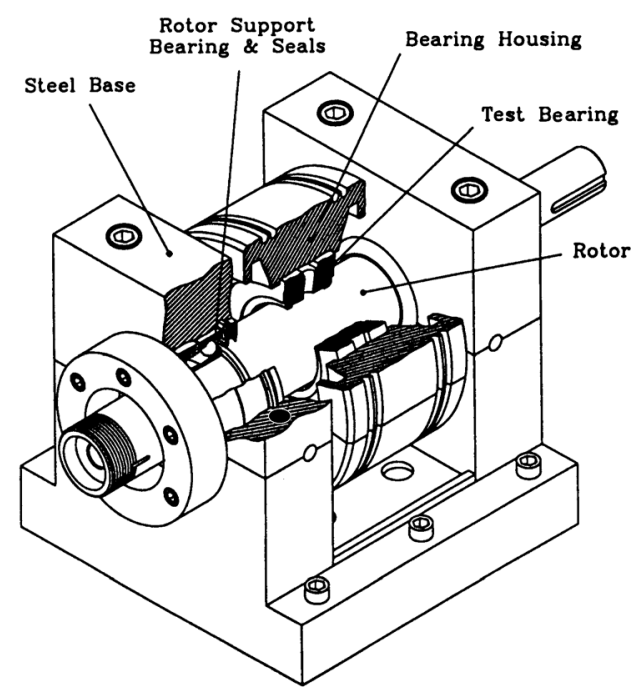

FIGURE 1 Housing with bearing.

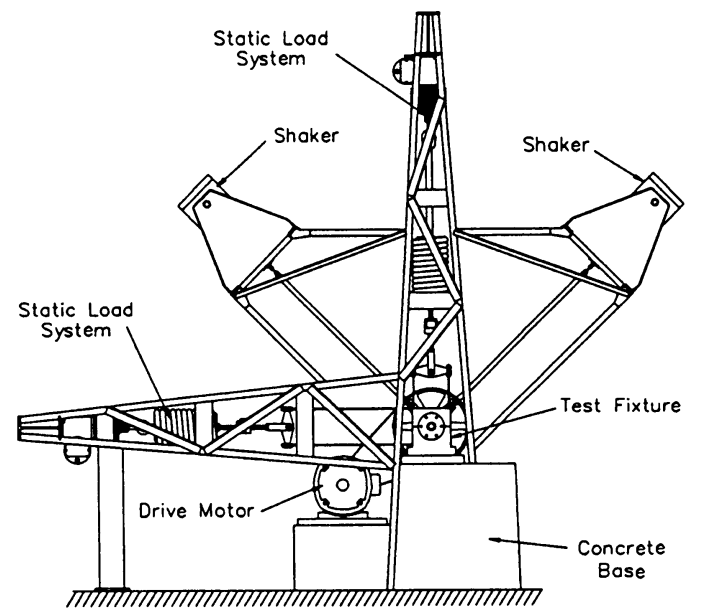

FIGURE 2 Test rig with load systems.
The axial groove bearing (Figure 3) was tested at two rotor speeds $(1125 \mathrm{rpm}$ and $1650 \mathrm{rpm})$ and the three-lobe bearing (Figure 4) was tested at three speeds $(900 \mathrm{rpm}$, $1439 \mathrm{rpm}$ and $1800 \mathrm{rpm}$ ). Four different steady radial loads were applied to each bearing at each speed ranging from approximately $50 \mathrm{~N}$ to $2000 \mathrm{~N}$. As a result, Sommerfeld numbers ranged from 0.065 to 2.865 .

The test rig was modeled as a two-degree-of-freedom system. The coefficients were determined from measured displacements and forces as described by Flack et al. (1993); matrix inversion of pairs of $4 \times 4$ response matrices was used to determine the bearing coefficients. Three orbits were applied at each operating point. Thus, determination of three complete independent sets of coefficients was possible by pairing the orbits three ways, i.e., orbits 1 and 2, 1 and 3 and 2 and 3 .

Both bearings were a one-piece assembly, with a steel shell and a babbitted running surface. The axial ends of the bearings were unsealed and operated at ambient pressure. Table I lists the bearing geometries, lubricant parameters, and other important operating conditions. Complete operating information for the experimental results, including

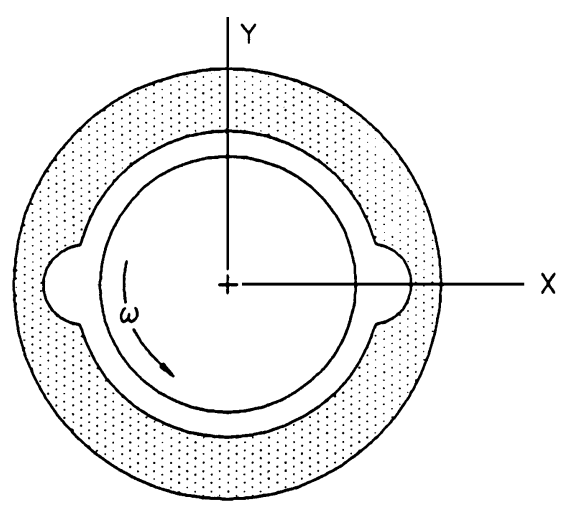

FIGURE 3 Axial groove bearing.

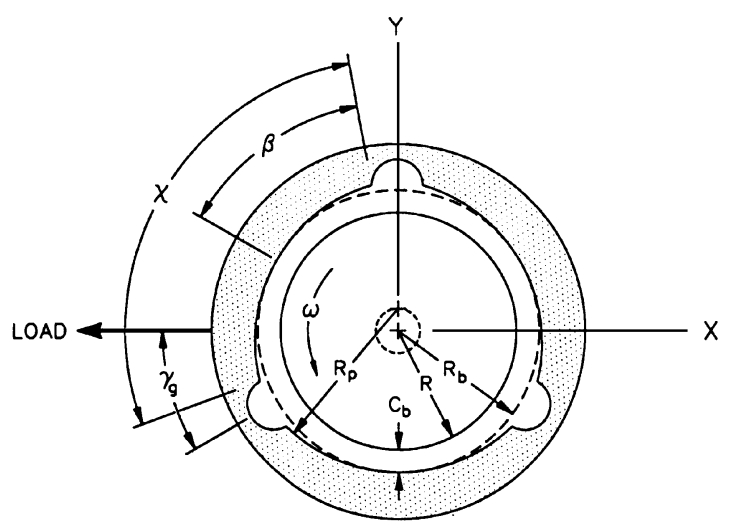

FIGURE 4 Three lobe bearing. 
TABLE I Bearing parameters

\begin{tabular}{lll}
\hline & Axial groove bearing & Three-lobe bearing \\
\hline Bearing Parameters & & $34.95 \mathrm{~mm}$ \\
Journal Radius & $34.95 \mathrm{~mm}$ & $0.093 \mathrm{~mm}$ \\
Radial Bearing Clearance, $c_{b}$ & $0.103 \mathrm{~mm}$ & 0.75 \\
Preload Factor & 0.00 & $52.1 \mathrm{~mm}$ \\
Length & $35.05 \mathrm{~mm}$ & $100^{\circ}$ \\
Pad Arc Length & $150^{\circ}$ & $30^{\circ}$ \\
Load Orientation, $\gamma_{g}$ & $90^{\circ}(\mathrm{on} \mathrm{pad})$ & 0.50 \\
Offset Factor & 0.50 & $65.00 \mathrm{~mm}$ \\
Bearing Outer Radius & $65.00 \mathrm{~mm}$ & $50.1 \mathrm{~W} / \mathrm{m}-{ }^{\circ} \mathrm{C}$ \\
Bearing Thermal Conductivity & $50.1 \mathrm{~W} / \mathrm{m}-{ }^{\circ} \mathrm{C}$ & $47.1 \mathrm{~W} / \mathrm{m}^{2}-{ }^{\circ} \mathrm{C}$ \\
Bearing Convection Coefficient & $47.1 \mathrm{~W} / \mathrm{m}^{2}-{ }^{\circ} \mathrm{C}$ & \\
Lubricant Parameters & & $0.0256 \mathrm{~N}-\mathrm{s} / \mathrm{m}^{2} \mathrm{at} 40^{\circ} \mathrm{C}$ \\
Oil Viscosity & $0.0256 \mathrm{~N}-\mathrm{s} / \mathrm{m}^{2}$ at $40^{\circ} \mathrm{C}$ & $0.0157 \mathrm{~N}-\mathrm{s} / \mathrm{m}^{2} \mathrm{at} 55^{\circ} \mathrm{C}$ \\
& $0.0157 \mathrm{~N}-\mathrm{s} / \mathrm{m}^{2}$ at $55^{\circ} \mathrm{C}$ & $0.149 \mathrm{~W} / \mathrm{m}-{ }^{\circ} \mathrm{C}$ \\
Oil Thermal Conductivity & $0.149 \mathrm{~W} / \mathrm{m}-{ }^{\circ} \mathrm{C}$ & $845 \mathrm{~kg} / \mathrm{m}^{3}$ \\
Oil Density & $845 \mathrm{~kg} / \mathrm{m}^{3}$ & $1.951 \mathrm{~kJ} / \mathrm{kg}-{ }^{\circ} \mathrm{C}$ \\
Oil Specific Heat & $1.951 \mathrm{~kJ} / \mathrm{kg}-{ }^{\circ} \mathrm{C}$ & \\
Operating Parameters & & 94.2 to $188.5 \mathrm{rad} / \mathrm{s}$ \\
Shaft Speed & $117.8 \mathrm{and} 172.8 \mathrm{rad} / \mathrm{s}$ & 56 to $977 \mathrm{~N}$ \\
Net Steady Load & 355 to $2016 \mathrm{~N}$ & $47.7^{\circ}-53.4^{\circ} \mathrm{C}$ \\
Oil Inlet Temperature & $49.4{ }^{\circ} \mathrm{C}$ & $21-36 \mathrm{kPa}$ \\
Oil Inlet Pressure & $18.6 \mathrm{kPa}$ & $47.1^{\circ}-54.2^{\circ} \mathrm{C}$ \\
Shaft Temperature & $48.9^{\circ} \mathrm{C}$ & $44.2^{\circ}-49.6^{\circ} \mathrm{C}$ \\
Bearing Outer Temperature & $45.0^{\circ} \mathrm{C}$ &
\end{tabular}

bearing loads, lubricant characteristics, oil supply pressure and flow rate, discrete temperature summaries, continuous film thickness and pressure profiles, experimental test procedures, and accuracies is provided by Kostrzewsky et al. (1996) and Taylor et al. (1995a, b).

\section{SUMMARY OF PREDICTION METHOD}

The theoretical analysis was developed by Branagan (1988) and includes variable viscosity effects in the lubricant film. The energy equation was coupled to Reynolds equation through an equation of state relating viscosity to both temperature and pressure. The cross-film viscosity variation was based on an assumed quadratic variation in temperature across the film. Temperature variation along the axial direction of the bearing film was assumed to be negligible. A polynomial form of the axial pressure distribution was assumed. Heat conduction and convection through the film and to the bearing shell and shaft were considered. The temperature at the leading edge of each pad was found using a simple mixing law for lubricant carried over from the preceding pad with that supplied to the oil feed grooves. The inlet supply temperature and that of the bearing shell neighboring the feed groove governed the temperature in the oil groove. The linearized stiffness and damping coefficients were obtained by solving a set of perturbation equations obtained from Reynolds equation for small motion about the equilibrium position for the applied steady loads.

\section{STABILITY PARAMETER AND WHIRL RATIO}

All of the dynamic coefficients were consolidated into a more understandable and condensed form. Namely, the linearized coefficients were used to find the rigid rotor stability threshold parameter, $\omega_{s}$ (which is the non-dimensional running speed at which the rotor is marginally stable) and whirl ratio, $\omega_{d}$ (which is the non-dimensional frequency at which the system would vibrate at the instability condition). These two parameters were originally derived by Lund and Saibel (1967) for both rigid and flexible rotors supported by bearings with a set of stiffness and damping characteristics. By solving the equations of motion, general case eigenvalues were determined. These were then evaluated for the case of marginal system stability. Results are:

$$
\begin{gathered}
\omega_{s}^{2}=B_{1} / B_{2} \\
\omega_{d}^{2}=B_{2}
\end{gathered}
$$


where

$$
B_{1}=\frac{\bar{K}_{x x} \bar{C}_{y y}+\bar{K}_{y y} \bar{C}_{x x}-\bar{K}_{x y} \bar{C}_{y x}-\bar{K}_{y x} \bar{C}_{x y}}{\bar{C}_{x x}+\bar{C}_{y y}}
$$

and

$$
B_{2}=\frac{\left(B_{1}-\bar{K}_{x x}\right)\left(B_{1}-\bar{K}_{y y}\right)-\bar{K}_{y x} \bar{K}_{x y}}{\bar{C}_{x x} \bar{C}_{y y}-\bar{C}_{x y} \bar{C}_{y x}}
$$

and where all of the coefficients $\left(\bar{K}_{x x}\right.$, etc.) are nondimensionalized. The above analysis was applied to both predictions and measured data. Thus, results are presented in "maps" in the following section. For example, the stability parameter is plotted vs. the Sommerfeld number and also plotted vs. the operating eccentricity. The curves on these maps represent the boundary between stable and unstable operation of the bearing with a non-flexible rotor. Namely, non-dimensional operating speeds with values larger than the stability parameter will be unstable. For flexible rotors the size of the stable region is reduced and the reduction is a function of rotor flexibility (Barrett, 1983).

To use the maps one first finds the speed parameter, $\omega \sqrt{c_{b} / g}$, and Sommerfeld number of an operating condition. The point is then plotted on the map to determine if the operating point is in the stable or unstable region. All tests that were performed for the data herein were well into the stable region with speed parameters less than one.

\section{DISCUSSION OF RESULTS}

Theoretical predictions are compared to the measured performance of an axial groove and a preloaded three-lobe journal bearing. Although the focus of this paper concerns stability, a few typical static operating characteristics are presented for completeness.

\section{Static Operating Positions}

The measured steady-state equilibrium positions are relative to the hot operating center of the axial groove bearing. In Figure 5 the eccentricity magnitudes are nondimensionalized by the bearing radial clearance, $c_{b}$, and presented. The graph shows the test data for two speeds as a function of Sommerfeld number. First, Figure 5 indicates that the journal position resides near the center of the bearing for high Sommerfeld numbers, or light loads, and moves outward to higher eccentricities as the Sommerfeld number decreases, i.e., load increases. Second, the test data from all three speeds essentially fall along the same curve. Third, at low values of Sommerfeld number (high loads),

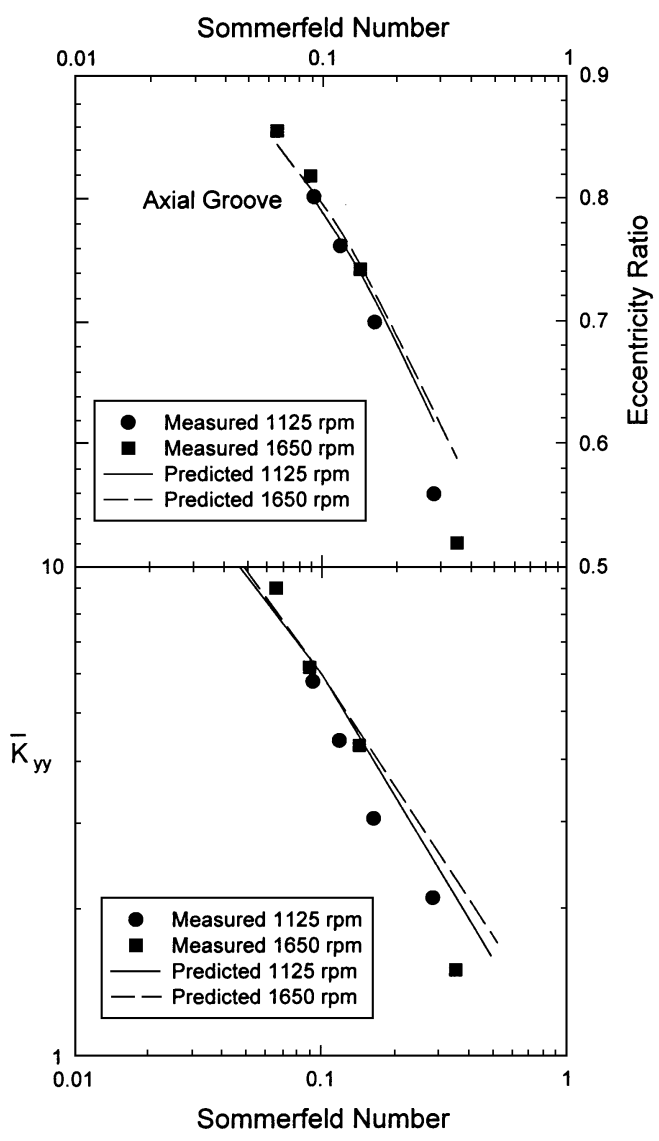

FIGURE 5 Comparison of $\bar{K}_{y y}$ and $\varepsilon v s$. $\mathrm{S}_{\mathrm{O}}$ for two rotational speeds for the axial groove bearing.

eccentricity ratios are under-predicted but as the Sommerfeld number increases (decreasing load), the eccentricity ratio test data is lower than predicted. Opposite effects were seen for the three-lobe bearing.

For both speeds, the analytic predictions fall very nearly along the same curve. The predicted positions exhibit the same general trend with increasing load as the experimental data. For Sommerfeld numbers below approximately 0.2, comparison of the experimental and analytic eccentricity ratios in Figure 5 shows the agreement to be within 0.02 . Also, the level of agreement remains relatively consistent for comparable Sommerfeld numbers for both speeds across the entire Sommerfeld number range.

\section{Dynamic Coefficients}

The eight stiffness and damping coefficients of the bearings were also measured by Kostrzewsky et al. (1994) and Taylor et al. (1995b); only one set of results is presented herein for the sake of brevity. Namely, $\bar{K}_{y y}$ is presented in Figure 5 as a function of Sommerfeld number for the axial groove bearing. This graph shows the measured and 
predicted values at two different constant speeds. For all eight of the dynamic coefficients, agreement between the numerical and experimental dynamic coefficients is very good, typically within $15 \%$ at Sommerfeld numbers less than 0.2. The magnitude and the slope of the coefficient vs. Sommerfeld number match well. Disagreement in coefficient magnitude by as much as $50 \%$ is seen at high Sommerfeld numbers for some coefficients, although general agreement in trends for the predicted coefficients vs. Sommerfeld number was always observed. Differences between the predicted curves for the two speeds are minimal.

\section{Stability Parameters}

Next, dynamic coefficients were used to find the rigid rotor stability parameter and whirl ratio and results are presented as functions of the Sommerfeld number in Figures 6 and 7. For the set of data reductions the nondimensionalized dynamic data was used to find individual stability parameters and whirl ratios. Only one theoretical curve is presented for each bearing type; the different theoretical curves agreed within the plotting accuracy.

Figure 6 illustrates that the theoretical stability predictions agree moderately with the experimental data but are almost entirely above the measured points for both bearing types. Experimental and theoretical curve shapes are very similar. The data indicate that the predicted characteristics are more stable than measured characteristics. For the axial groove bearing the experimental values of Sommerfeld number for which infinite stability is exhibited range from 0.089 to 0.11 , while the predicted value is 0.084 . For the three-lobe bearing the experimental values of Sommerfeld number for which infinite stability is exhibited range from 0.63 to 1.2 , and the predicted value is 1.1 . The axial grove

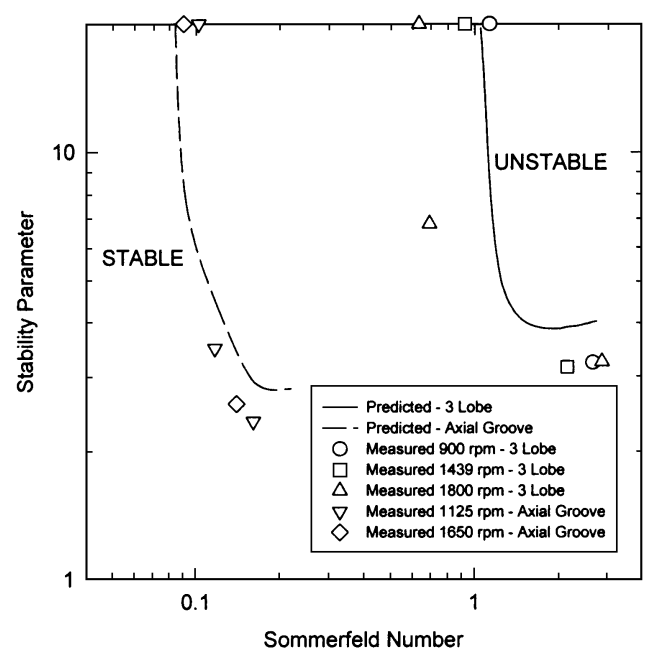

FIGURE 6 Stability parameter as a function of Sommerfeld number.

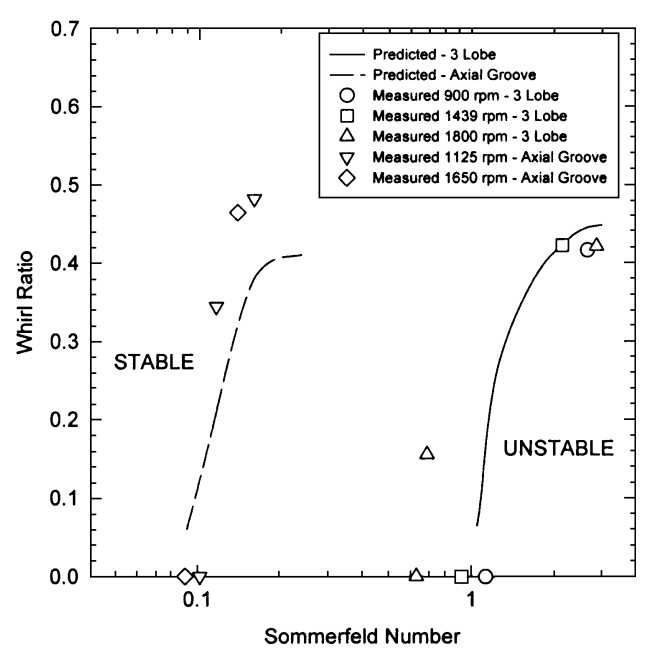

FIGURE 7 Whirl ratio as a function of Sommerfeld number.

bearing is considerably less stable than the three-lobe bearing, since the stability region is greatly reduced. In Figure 7 the theoretical whirl ratio predictions are typically lower than measured data for low Sommerfeld numbers but close to measured data for high Sommerfeld numbers.

To further investigate agreement between the predictions and measurements, $\omega_{s}$ and $\omega_{d}$ were also plotted versus $\varepsilon$. This method of correlation was used to determine if, for a given static operating location, predictions and measurements agree. Such data are presented in Figures 8 and 9. As can be seen in Figure 8, the theoretical stability predictions again are above the experimental data indicating that the predicted bearing characteristics are more stable than measured characteristics. For the axial groove bearing the experimental values of eccentricity ratio for infinite stability range from 0.78 to 0.82 , while the predicted value is 0.82 . For the three-lobe bearing the experimental values

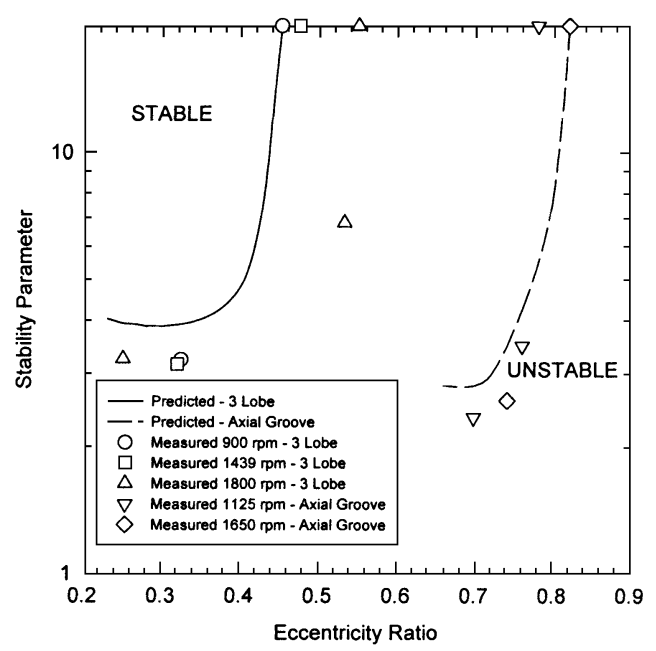

FIGURE 8 Stability parameter as a function of eccentricity ratio. 


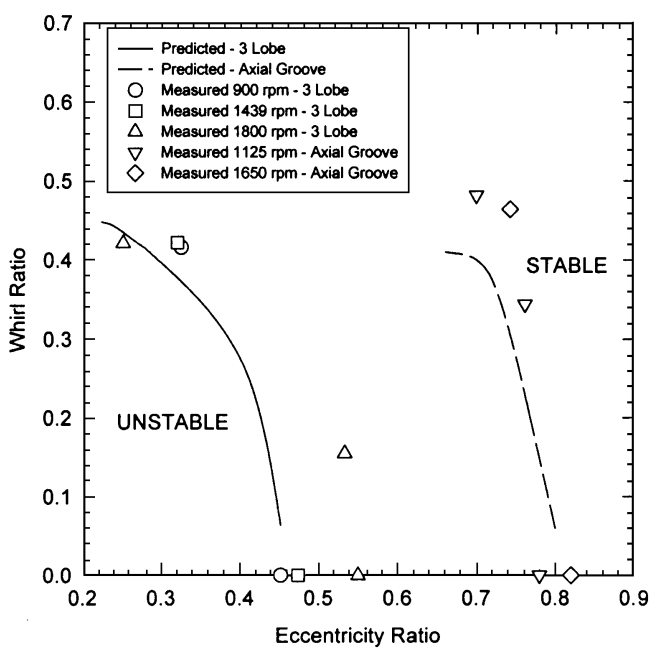

FIGURE 9 Whirl ratio as a function of eccentricity ratio.

of eccentricity ratio for infinite stability range from 0.45 to 0.55 , while the predicted value is 0.45 . Again, experimental and theoretical curve shapes are very similar. In Figure 9 the whirl ratio predictions are typically lower than measured data for high eccentricity ratios (low Sommerfeld numbers) but close to experimental data for low eccentricity ratios. Hence, for this alternative method of comparing predictions to measurements, better agreement was not found.

\section{SUMMARY}

Experimentally measured static operating characteristics and dynamic coefficients of an axial groove bearing and a preloaded three-lobe journal bearing were compared to predictions for a range of Sommerfeld numbers. The eight experimental linearized bearing coefficients were derived from different force and motion orbits. The rigid rotor stability parameters and whirl ratios were found from the non-dimensional coefficients. The results provide a designer a moderate level of confidence in modeling the dynamic stability for Sommerfeld numbers less than about 3.0 for the 3-lobe bearing and 0.2 for the axial groove bearing.

Agreement between measured and predicted eccentricity ratios is very good, within 0.02 to 0.09 . Agreement between numerical and experimental dynamic coefficients is best at low Sommerfeld numbers. At high Sommerfeld numbers, differences over $50 \%$ in magnitude were sometimes seen.

The experimental and theoretical rigid rotor stability parameters were independently plotted versus (i) the Sommerfeld number and (ii) the static eccentricity ratio. For both correlation methods, comparisons indicate that for a given Sommerfeld number, the predicted bearing is more stable than measurements indicate. Similarly, these comparisons also show that for a given eccentricity the analysis predicts greater stability than measured. Neither correlation method provided superior agreement between predictions and experimental measurements. The whirl ratio predictions are typically lower than measured data for high eccentricity ratios (low Sommerfeld numbers) but close to experimental data for low eccentricity ratios. As expected, the stability of the axial groove bearing was significantly lower than the three-lobe bearing.

\section{NOMENCLATURE}

\section{$c_{b}$ \\ $c_{p}$
$B_{1}, B_{2}$}

C

$\bar{C}=C \omega c_{b} / W$

$D$

$e$

$g$

$K$

$\bar{K}=K c_{b} / W$

$L$

$m=c_{b} /\left(R_{b}-R\right)$

$N$

$R$

$R_{b}$

$R_{p}$

$S=\mu N D L R^{2} /\left(W c_{b}^{2}\right)$

$W$

$\alpha$

$\beta$

$\varepsilon$

$\gamma_{g}$

$\mu$

$\chi$

$\omega$

$\omega_{d}$

$\omega_{s}$ radial bearing clearance for a centered shaft

pad (lobe) radial clearance

parameters in calculation of $\omega_{d}$ and

$\omega_{s}$

damping coefficients $\left(C_{x x}\right.$, etc. $)$

dimensionless damping coefficient

shaft diameter

eccentricity of the shaft from the

bearing center

gravitational constant

stiffness coefficients $\left(K_{x x}\right.$, etc. $)$

dimensionless stiffness coefficient

bearing length

bearing preload factor

rotational speed

shaft radius

bearing radius

pad radius

Sommerfeld number

total bearing load

pad offset factor, $\alpha=\beta / \chi$

angle between pad leading edge and

minimum film

eccentricity ratio, $\varepsilon=e / c_{b}$

angle between load and oil groove

absolute viscosity

pad angle

rotational speed

whirl ratio parameter

rigid rotor stability parameter

\section{REFERENCES}

Barrett, L. E. (1983) "The Optimization of Hydrodynamic Journal Bearings for Aerodynamically Excited Flexible Rotor-Bearing Systems", ASME Transactions. Journal of Mechanical Design, 105(2), $227-232$.

Branagan, L. A. (1988) “Thermal Analysis of Fixed and Tilting Pad Journal Bearings Including Cross-Film Viscosity Variations and Deformations", Ph.D. Dissertation, University of Virginia, Charlottesville, VA. 
Flack, R. D., Kostrzewsky, G. J. and Taylor, D. V. (1993) “A Hydrodynamic Journal Bearing Test Rig with Dynamic Measurement Capabilities”, Tribology Transactions, 36(4), 497-512.

Flack, R. D. and Kostrzewsky, G. J., "A Comparison of the Experimental and Predicted Rigid Rotor Stability Threshold of a Highly Preloaded Three Lobe Bearing", IFToMM International Conference on Rotordynamics, 7-10 September, 1998. Darmstadt, Germany, Proceedings, pp. $501-512$.

Kostrzewsky, G. J., Taylor, D. V. and Flack, R. D. (1994) "Experimental Determination of the Dynamic Characteristics of a Two-Axial Groove Journal Bearing”, Tribology Transactions, 37(3), 534-542.

Kostrzewsky, G. J., Flack, R. D. and Barrett, L. E. (1996) "Comparison Between Measured and Predicted Performance of a Two-Axial Groove Journal Bearing", Tribology Transactions, 39(3), 571-578.

Kostrzewsky, G. K., Taylor, D. V., Flack, R. D. and Barrett, L. E. (1998) "Theoretical and Experimental Dynamic Characteristics of a Highly Preloaded Three-Lobe Journal Bearing", Tribology Transactions, 41(3), $392-398$.
Lanes, R. F. and Flack, R. D. (1982) "Effects of Three-Lobe Bearing Geometries on Flexible Rotor Stability", ASLE Transactions, 25(3), $377-385$.

Lund, J. W. and Saibel, E. (1967) "Oil Whip Orbits of a Rotor in Sleeve Bearings", ASME Transactions. Journal of Engineering for Industry, 89(4), 813-819.

Swanson, E. E. and Kirk, R. G. (1997) "Survey of Experimental Data for Fixed Geometry Hydrodynamic Journal Bearings", ASME Transactions. Journal of Tribology, 119(4), 704-710.

Taylor, D. V., Kostrzewsky, G. J., Flack, R. D. and Barrett, L. E. (1995a) "Measured Performance of a Highly Preloaded Three-Lobe Journal Bearing - Part I: Static Characteristics", Tribology Transactions, 38(3), $507-516$

Taylor, D. V., Kostrzewsky, G. J., Flack, R. D. and Barrett, L. E. (1995b) "Measured Performance of a Highly Preloaded Three-Lobe Journal Bearing-Part II: Dynamic Characteristics", Tribology Transactions, 38(3), $707-713$ 

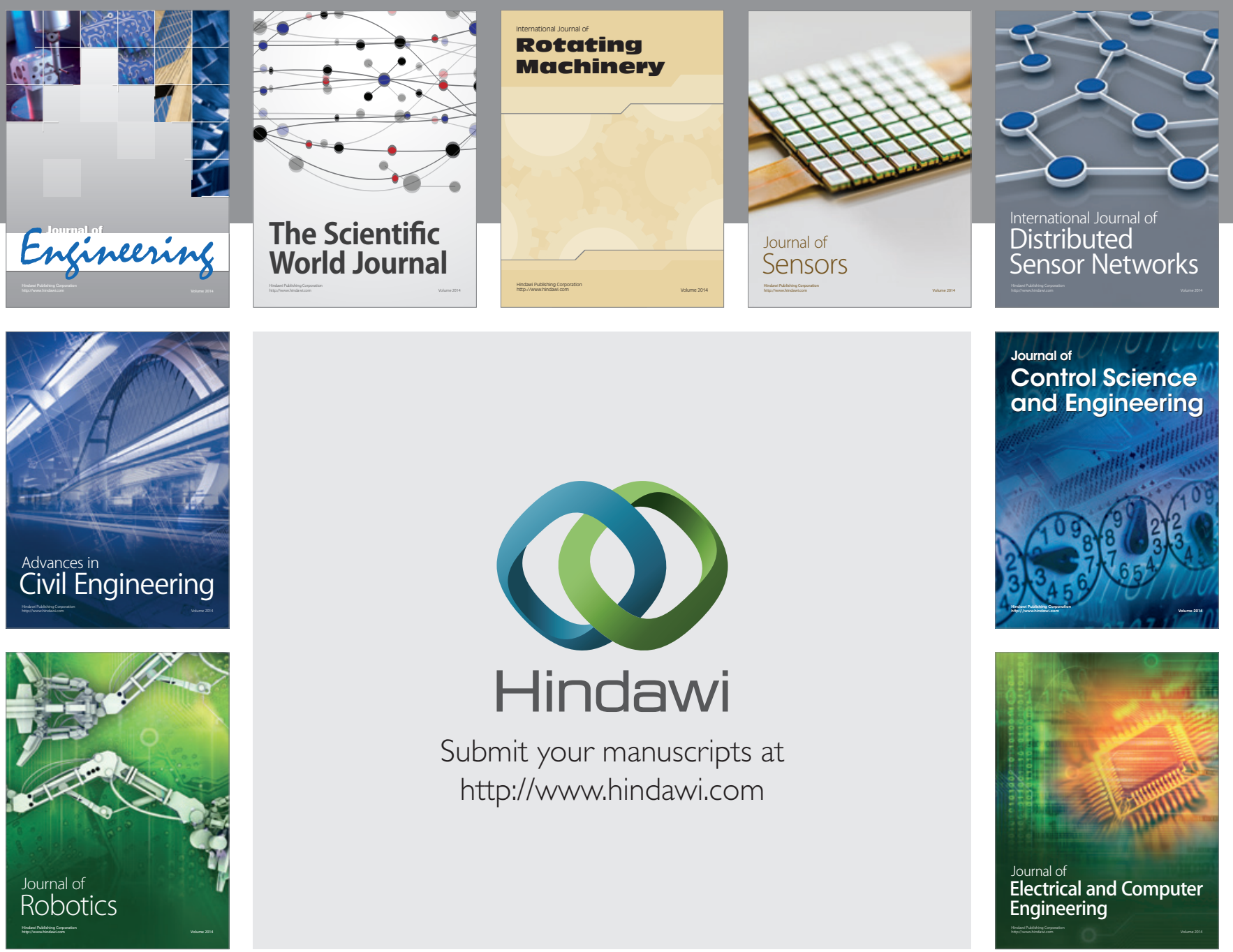

Submit your manuscripts at

http://www.hindawi.com
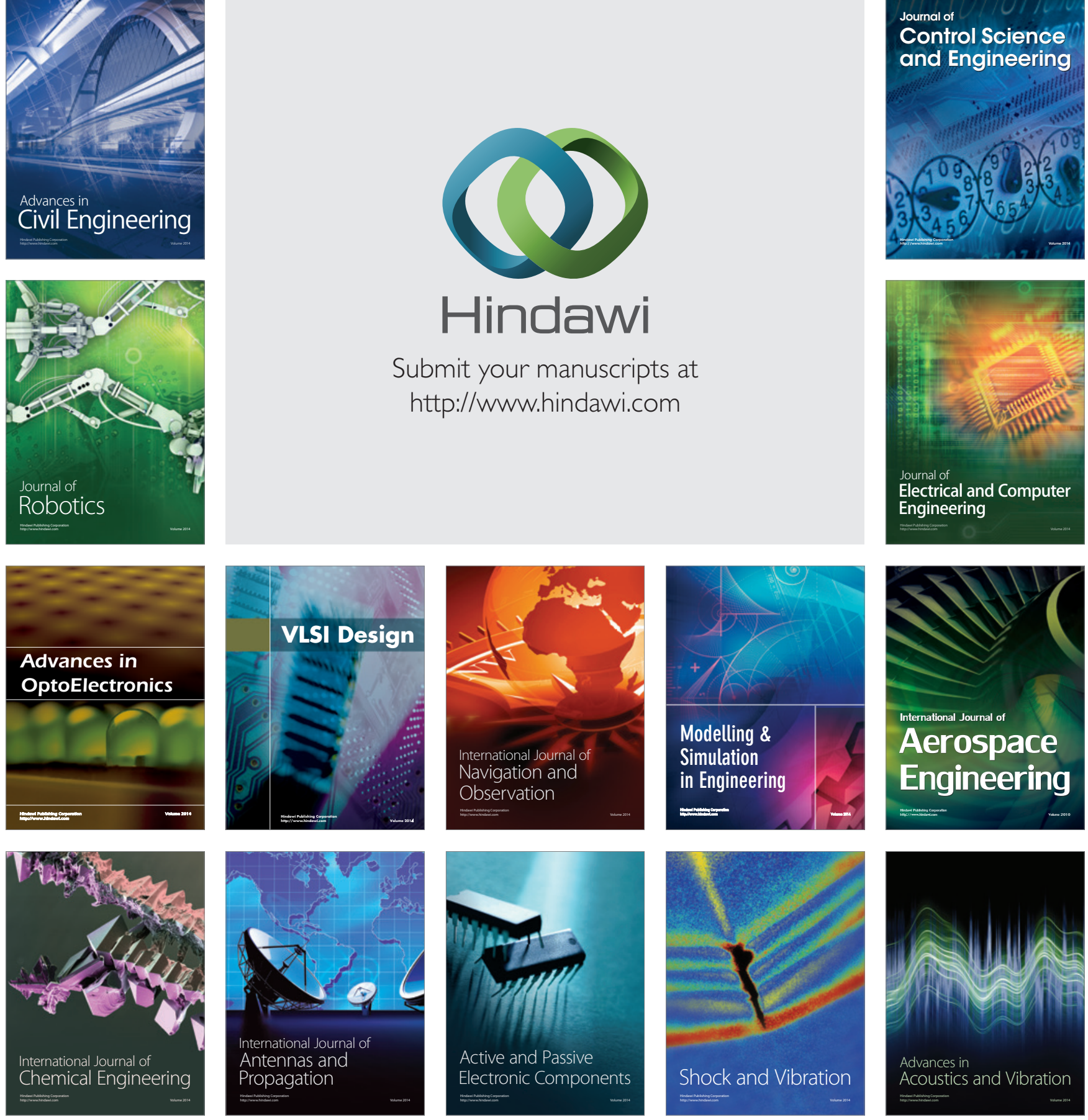